International Journal of Linguistics, Literature and Translation

ISSN: 2617-0299 (Online); ISSN: 2708-0099 (Print)

DOI: 10.32996/ijltt

Journal Homepage: www.al-kindipublisher.com/index.php/ijltt

\title{
A Meta-Analysis of Studies on the Effectiveness of Using Games Strategies in English Language Learning and Teaching
}

\author{
Emad Ayyad Al Soufi ${ }^{1}$ (D) $\triangle$ and Ali Farhan AbuSeileek ${ }^{2} \mathbf{Q}(D)$ \\ ${ }^{1}$ Ministry of Education, Jordan \\ ${ }^{2}$ Professor of TEFL, Al al-Bayt University, Jordan
}

$\triangle$ Corresponding Author: Emad Ayyad Al Soufi, E-mail: waseem2008asel@yahoo.com

\author{
ARTICLE INFORMATION \\ Received: August 08, 2021 \\ Accepted: September 20, 2021 \\ Volume: 4 \\ Issue: 9 \\ DOI: $10.32996 /$ ijllt.2021.4.9.18
}

\section{KEYWORDS}

Games, Meta-analysis, Effectiveness, English Language Teaching

\section{ABSTRACT}

This study aimed to identify the general trends, description and focus of research about the effectiveness of using games strategy in English language teaching and learning. That is, it investigated the strategies used, instrument, year of publication, publication type, participant, design of the study, skills and areas analyzed in the study, and length of text in studies about the effectiveness of games method. The study used a meta-analysis research design in data collection and analysis. The sample of the study consisted of 70 journal articles, conference proceedings, and graduate theses and dissertations published between 2000-2018. The instrument of the study was a meta-analysis checklist. The descriptive statistics, including frequencies and percentages were used to find differences between the different features. The findings revealed that strategies used in this study and, the feature games (regular) method had the highest frequency. Moreover, the test instrument had the highest frequency in the sample studies analyzed. However, the year 2016 obtained the highest frequency for the year of the study. The type of publication got the next highest frequency in favour of conference proceedings. This was followed by the participant type and level features (EFL learners, school, and 16 participants and more) in the study sample. The experimental design of studies about games strategies received a high frequency. There was also the frequency for skills and areas in studies about games strategies in favour of reading. The feature games are more effective than other methods and the text length of 11 to 20 pages (2,645-4,729 words) category had the highest frequency. Finally, several related recommendations were introduced to the researchers, curricula designers, supervisors, and English teachers.

\section{Introduction}

This previous decade has witnessed the development of knowledge technologies with the improvement of games. With the development of education-based technology, there is an instant need to examine the effect of using games-assisted learning. Many studies for using games become invisible, which requires criticism to show outlook research and discover the elements of effectiveness on learning. Using games is also in need of a review of the literature. English is one of the most essential languages in different contexts, including English as a foreign language (EFL) and (ESL). It is a lingua franca in this world, and learner needs it to develop and improve their linguistic and communication skills. Researchers and English language teachers try to find new contemporary strategies for teaching the English language to make learning more effective for students. This study is based on a meta-analysis to discover the effectiveness of using game strategies in English language learning and teaching.

\section{K C AL-KINDI CENTER R D FOR RESEARCH AND} Your gateway to world-class research

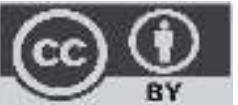

Published by Al-Kindi Center for Research and Development, London, United Kingdom. Copyright (c) the author(s). This open access article is distributed under a Creative Commons Attribution (CC-BY) 4.0 license 


\subsection{Games and English language teaching and learning}

Games are considered a new strategy in the time of growing knowledge and information where the Internet and computer have opened many ways of amusement and learning of students. Games also play an essential role to enhance students. Also, students spend much time playing games. Accordingly, this paper focuses on meta-analysis of studies about the effect of games on developing learners' English language. According to Bacha (2002), games are authoritative tools for teaching the English language that encourages learning through simulating the students' intrinsic motivation. However, teachers need to study which games to use, how to connect them with the syllabus, program or textbook, and how students benefit from games in different ways. Atake (2003) pointed out that students were helped by using educational computer games by practising English in daily life situations and the English language classroom. Additionally, educational games help all students to learn and practice the English language without being afraid. Based on Doughty and Long (2003), instruction focuses on what learners ought to recognize to accomplish explicit tasks. The task-based approach is highly applicable for game-based learning environments. The task-based approach carries over the skill builder lesson. Similarly, the lesson is centred on getting explicit skills relevant to explicit sorts of things. The content development technique used for content expressly takes this into consideration.

According to Duff (2007) and Tarnoe (2007), games have many_benefits that make them effective aspects in learning, such as socialization and collaboration, motivation, engagement, and they negotiated that these aspects improve language learning teaching. The increasing importance of game-assisted learning has attracted interest from researchers. For example, Kebritchi and Hirumi (2008), and Ke (2009) showed that the number of studies dealing with game-assisted learning has improved over the past few decades. Games inspire students to direct their energy towards language learning by providing meaningful contexts (Wright, Betteridge \& Buckby, 1984). However, academics must see games as time fillers or tools designed for entertainment and integrate them into their foreign teaching programmes. Rixon $(1991$, p.3) demonstrated that games are a kind of play which is governed by certain rules." Likewise, Hadfield (1990) demonstrated that games are activities with goals, rules and elements of fun.

\subsection{Meta-analysis}

In most systematic reviews, Borenstein and Hedge (2011) refer to meta-analysis as a key element in statistical data synthesis or meta-analysis. Unlike the narrative, in which reviewers implicitly assign a certain level of importance to each study, the weights assigned to the research are based on mathematical criteria defined in advance in the meta-analysis. Although reviewers and readers may still disagree on the practical significance of the result (as they might do for a primary study), the statistical analysis provides a straightforward, objective, and replicable context for this debate.

The systematic review may also play a part in any new primary research being performed. In the publication introductory a systematic review will help to contextualize the new study by explaining what we learned before and what we expected to know from the new study systematic review in the discussion section of the journal allows us to examine not only the information provided by the new study but also the body of evidence as provided by the new study. lain Chalmers and Michael Clarke (1998) see this approach to avoid disclosing studies that refer to "Islands in Search of Continents" without meaning. This background would be generated by systematic reviews more thoroughly and transparently than the narrative analysis usually used to this end.

The term meta-analysis defined by Glass (1976) refers to the "analysis of analyzes" or, more specifically, the "statistical analysis of a large collection of empirical results from individual studies to incorporate the findings" (p. 3). However, Hunter, Schmidt, and Jackson (1982) clarify that meta-analysis is a research technique that is used to synthesize different research results from several studies related to the same topic. Thus, the research findings from primary studies serve as the raw data in a meta-analysis. The meta-analysis could lead to a more comprehensive overview of the same research topic based on the analysis and integration of these findings. In a meta-analysis, a quantitative method is typically applied to estimate the correlation between variables through statistical evaluation to deliver accurate and comprehensive outcomes.

Stern and Harris (1985) propose a new method of meta-research: a qualitative meta-analysis, often called meta-synthesis. In contrast to quantitative meta-analysis, the qualitative meta-analysis approach is considered not merely aggregative but interpretive (Noblit \& Hare, 1988), offering more detailed information to address the research questions specifically. Given the variety of methods and resources used to determine the efficacy of using games to improve language learning, statistical techniques to code and synthesize results can generate bias. Therefore, a systematic meta-analysis has been applied to provide a thorough overview of current literature in the last five years. This research paper follows the universal meta-study protocol outlined by Paterson, Thorne, Canam and Jillings (2001), who suggested a method based on formulating research questions, choosing primary 5 researching, perform a meta-data analysis, employing a meta-method, and then establishing a metasynthesis and dissemination. 
Meta-analysis is a method of doing a systematic review of related literature using statistical methods. This study introduces meta-analysis and integrates this method into their own research whenever an effect size can be calculated from a study. It introduces a meta-analysis as a method for investigating the effectiveness of using games techniques in English language learning, calculating effect size and the ability to interpret the results of a meta-analysis study.

Norris and Ortega (2000) pointed out meta-analysis is a means of synthesizing quantitative results across several empirical studies that deal with the same or closely related research questions. When the data are produced from experimental or quasiexperimental studies, it is restricted to analyze an accumulation of such data by voting to count. In other words, it is limited to measure how many studies showed statistically significant positive effects, negative effects or no significant effects for a specific variable or language education intervention. Vote counting can not take into account study-wide disparities such as variations in sample size. Meta-analysis takes these differences into account across studies. It allows the data from different studies representable on a single common scale, allowing for both the creation of a weighted effect size taking these differences into account across studies and the investigation of whether such possible moderating variables affect the efficacy of certain interventions.

Paterson, Thorne, Canam and Jillings (2001) made a general procedure of the meta-study, which needs analyzer to formulate research queries, choose primary 5 types of research, perform a metadata analysis, and use a meta-method to produce a metasynthesis and dissemination. This ensures the reliableness and validity of the findings. Porenistein, Hedges, Higgins, and Rothestien (2009) reported that the primary step in meta-analysis is to calculate impact size from each study. Since quite one impact size in an exceedingly single study inflate sample size, lose the independence of knowledge points, and cause distortion of ordinary error, only one impact size per study may be enclosed for a meta analysis.

Meta-analysis is based on the quantitative procedures that statistically mix the results from studies on the constant topic to achieve general conclusions concerning the consequences or outcomes of a given treatment, project, or program (Cooper, 2009; Glass, Mc Gaw, \& Smith, 1981). Many meta-analysis-based studies are conducted to analyze the consequences of language programs on tutorial action of language minority kids within the USA. This study is based on meta-analysis of studies about the effect of games on developing students' language learning.

\subsection{Problem of the study}

The use of games strategy has witnessed an enormous increase in the last few years. Thus, researchers have been a common practice in the last few years to depend on games strategies as one of the technology developments in English language teaching. The description of research about game strategies is a very crucial issue. However, it has been addressed by researchers all over the world in single studies. This has made it difficult to have a clear picture of the uses of games in English language teaching, especially their general trends, description and focus. Additionally, many researchers are convinced of the effectiveness of using games in English language learning. For this purpose, I identify the use of meta analysis to assess the results of effectiveness in order to highlight the advantages of using games.

The use of meta-analysis research is one of the researchers that has not been adopted much in researchers. This research design conducted much work and effort as it may be one of the most difficult research designs. This study conducts the general trends, description and focus of the previous studies about using games in ESL/EFL.

\subsection{Objective and question of the study}

The goal of this study to introduce the general trends, description and focus of research on games studies. Thus, it investigates the strategies used, instrument of the study, year of publication, publication type, participant, design of the study, skills and areas analyzed in the study, and length of text, and effectiveness of game method. This study tries to answer the following question: What are the general trends, descriptions and focus of research of using games strategies in English language teaching and learning related to the following features: strategies used, instrument of the study, year of publication, publication type, participants, design of the study, skills and area, length of study, and effectiveness

\subsection{Significance of the study}

This paper used a meta analysis of the effectiveness of using games strategies in English language teaching. The most important of this study is that it conducts most research based on games strategy to discover its effects on a specific area or evaluate its aim. It also provides a comprehensive picture of what exactly would be investigated in different features. Additionally, the findings of this study may be beneficial for researchers to know what is possible to be used in English language skills and areas through games strategies. I hope this research is helpful to teachers in planning their studies based on what has already been done in the area of games. It may strengthen existing findings of the effect of games on developing students' English language. Games can be used to facilitates teachers' plan, after and during class. It may save the time for teachers. 


\section{Related literature}

\subsection{Review of related studies about meta analysis in English language}

Slavin and Cheung (2003) recently reviewed studies about teaching methods of reading to English Language Learning (ELL) students, comparing the practice of teaching ELLs first to read in their native language (a bilingual education strategy) with that of teaching them first to read in English (a strategy for immersion). Following a broad search for all studies involving ELL students, partially assisted by external organizations, Slavin and Cheung selected studies based on the following criteria: (a) the studies compared children taught reading in bilingual classes with those taught in English immersion classes; (B) either random assignment to conditions or pre-testing or other matching criteria established the degree of comparability of bilingual and immersion groups prior to commencement of treatment; (c) participants were ELLs in English-speaking primary or secondary schools; (D) the dependent variables included quantitative measurements of English-reading results, such as standardized testing and informal reading inventories; and (e) the period of treatment was at least one school year. Slavin and Cheung listed 16 studies that met these requirements, published in the period 1971 to 2000 . A study by Slavin and Cheung concluded that the evidence on balance favors bilingual approaches, particularly combined bilingual approaches that simultaneously teach reading in the native and English languages. Most of the research that they considered methodologically appropriate favored bilingual approaches over immersion approaches; though some found no difference, none favored immersion programs substantially.

Felix (2005) conducted a study providing a comprehensive picture of the efficacy of CALL between 2000 and 2004 , and the study found why this problem is so difficult to answer the question produced 52 studies published in the last four years alone. The research explores perspectives, strengths and weaknesses in this work body and establishes examples of good practice of architecture. He used meta analyzes to determine clear results of cause and effect, based on the size of the effects. The study findings stressed that a series of systematic findings syntheses related to one particular variable, such as learning strategy or writing quality, could generate more valuable insights into the crucial effect of technologies on learning processes and outcomes and propose a research agenda along these lines.

Natalie (2010) conducted meta-analysis to characterize differences in language ability between children born very preterm (VTP, 32 weeks gestational age) with a very low birth weight (VLBW, 1500g), or both and in term-born children. Electronic debates were systematically searched, and twelve studies met the inclusion criteria. Effect sizes were calculated to compare VPT/ VLBW and control children. The result VPT/ VLBW children performed between 0.38 and 0.77 below control subject in the area of perceptive and expressive language. The results of perceptive and expressive grammar were equivocal.

Yun (2010) conducted a study to synthesize the characteristics of technology usage studies and empirical studies methods for a comprehensible and informative analysis of the impact of hypertext glosses on vocabulary acquisition of second-language English learners. The study showed the impact of the hypertext gloss on the acquisition of L2 vocabulary using a meta analysis approach. Meta analysis as a quantitative approach for synthesizing overall findings from 300 empirical studies by calculating a standardized mean effect size. The results revealed that different second language learners, including English as a second or foreign language, enjoy multiple glosses of hypertext while reading computerized text.

Han and Cheng (2011) meta studied for 3 years eight high school English Language Learners (ELLs) from 2 Ontario high schools located in small Ontario cities and investigated their linguistic, cognitive, and socio-cultural learning experiences closely. Each student was visited 2-4 times a year, and each visit used face-to-face interviews. It was found that the challenges these students face in academic English were the main challenge to their performance in their high school subjects and the Ontario Secondary School Literacy Test (OSSLT). In turn, these challenges impacted their educational goals. The findings of this study provide a vivid explanation of the educational achievement of these students, as they concurrently learned English and their subject-area courses in the sense of the OSSLT - a high-stakes literacy test on a large scale.

Steve (2011) analyzed of 29 experimental and quasi-experimental studies conducted with grade 1-12 students to investigate whether process writing instruction enhances the writing quality and motivation of the students to write. System writing instruction resulted in a statistically significant but relatively modest, increase in overall writing efficiency for students in general education classes (average weighted impact size [ ES ] = 0.34). Variation in ES was not related to the grade, reliability of the measure of writing quality, professional development, evaluated genre or research quality. The method writing strategy resulted in neither a statistically significant increase in the students' motivation nor improved the quality of the compositions of the struggling authors.

William (2011) analyzed empirical literature on the influence of accents of speakers on interpersonal assessments. The analysis of the published literature identified 20 studies that compared the effects of standard accents (i.e., the recognized accent of the majority population) to non-standard accents (i.e. accents deemed alien or spoken by minorities) on speaker evaluations. These 20 experiments yielded 116 separate sizes of effects on a variety of characteristics that original researchers picked. We 
categorized each of the characteristics as belonging to one of the three realms traditionally discussed in this context, namely status (e.g., intellect, social class), solidarity (trustworthiness, in-group member) and dynamism (active level). The impact was particularly strong as compared to non-standard accented speakers by the American Network. Such findings underline previous research showing that speakers' accents have powerful effects on how others interpret them. In the literature background, these and other findings are discussed along with implications for future research in this area.

Ayaz and Şekerci (2015) metaanalyzed studies aiming at defining the special effects of the constructivist learning approach on learners' academic achievement, including linguistics achievement. International databases, master thesis, doctoral dissertation and articles in national, which are understood between 2003-2014, appropriate to the problem and which can be involved in a study of meta analysis with important statistical data, have been studied by examining in English and Turkish. Lastly, of the literature review, 53 studies about the effects of the constructivist learning approach on learners' academic achievement have been involved in the meta analysis study. Consequently, of moderator analyses, they saw that the highest effect values witnessed in the master's thesis were in the instruction of subjects including language at the college level.

Nematollahi, Behjat, and Kargar (2017) carried out a study that was a meta-analysis of a body of 30 research projects on the vocabulary learning strategies of EFL learners. The study's design has a descriptive and qualitative design because it describes and measures a treatment's effectiveness. The basic point of studying was a second language. The goal of the study was also to find the link between factors such as context, care, research method and vocabulary learning and the use of strategy. Study results showed that students ' techniques are as follows: commitment, cognitive, memory, meta cognitive, and social strategies. It also seems that contextualization and the use of the dictionary are amongst the techniques that successful students favor. On the other hand, the relationship among context, methodology and treatment by vocabulary learning approach were used.

\subsection{Review of related studies about using meta analysis in games}

Vogel and Bowers (2006) conducted a meta-analysis to determine which teaching methods, games and interactive simulations or traditional methods of teaching the English language were dominant and under what conditions. Potential studies have been selected from computerized databases (Psyclnfo, ERIC, ACM, and Google), dissertation abstracts, and back searches from the reference lists of articles collected. Each study must have identified cognitive gains or attitudinal changes as one of its main hypotheses for inclusion in the analysis. Each study also required reporting statistics evaluating traditional classroom teaching versus computer gaming or teaching on interactive simulation. Two effect sizes for the overall results have been compiled. The data suggested that cognitive gains were significantly higher overall in subjects using interactive simulations or games versus traditional teaching methods $(z=6.051, p<.0001(\mathrm{~N}=8549))$. The fail-safe number $(\mathrm{Nfs})$, or the number of undiscovered studies needed to change this hypothesis with opposing findings, was 1465 , so that finding was reliable a major effect for attitude was also observed $(z=13.74, p<.0001)(N=2378)$, Nfs = 117) consistently indicating that the attitudes of subjects towards learning were significantly better when using computers than those using traditional teaching methods.

Liao (2010) meta analyzed existing research comparing game-based learning (GBL) to traditional instruction (TI) effects on the achievement of English language which used by students in Taiwan. Thirty-eight studies were from four sources, turning their quantitative data into an Effect Size (ES). For all 38 trials, the average grand mean of the study-weighted ES was 0.39 . The results suggest GBL in Taiwan is more efficient than TI. Furthermore, 10 of the 15 characteristics of the sample chosen for this study had a statistically important effect on mean ES. The results of this study indicated that GBL's effect over TI is positive. Several moderator variables were also evaluated to check the results when game-based learning was being applied in educational environments.

Sitzmann (2011) synthesized result results from sixty five studies from 1976 to 2009, that specialize in pretest-posttest comparisons of self-efficacy, declarative information, procedural information, and retention in simulation Games, Design, and Learning 81 games for adult hands trinees. Sitzmann outlined simulation games as "instruction delivered via pc that immerses trainees in a very decision making exercise in a man-made atmosphere so as to find out the results of out the results of very decision making exercise in a man-made atmosphere so as to find their decisions" (p. 492). Comparison conditions within the synthesized from no-training management conditions to different tutorial methodology conditions. Theoretical moderator variables enclosed diversion price, whether or not the simulation game instruction was active or passive, whether or not the trainees had unlimited access to the simulation game trainees had, whether or not the simulation game was the sole tutorial methodology, and whether or not the educational strategies within the comparison cluster were active or not passive, method moderator variable enclosed random assignment to condition, rigor of the study style publication standing, and year of the presentation. 
Abd Razak (2013) analyzed many current articles published by a selected journey by focusing on studies of the capacity of vocabulary training by international students in Bahasa Melayu video games. Articles published between 2013 and 2013 include those in journals such as Computer and Education, Computers in Human Behavior, Educational Technology Research Development, procedia social and behavior science, Australian journal language and literacy, Computer Assisted Language Learning, educational technology, culture and Educational research Journal in Scandinavia. Only fifteen of the thirty-three papers published between 2003 and 2011 have been based on this research. Nevertheless, the keywords video games and language learning were used to identify only 9 articles. Most of the papers were literature reviews regarding methodology, followed by case studies and experimental studies. Several papers mixed quantitative methods with qualitative approaches. Findings from all the articles reviewed show that video games have the potential to be effective teaching aids and can motivate students to learn languages.

Rosman, Alias, and Siraj (2013) meta analyzed several current articles published by selected journals focusing on studies related to the potential of international students to learn vocabulary in Bahasa Melayu video games. Among the articles in the journals are those published in Computers and Education, Computers in Human Behavior, Education Technology Research Development, Procedia Social and Behavioral Sciences, Australian Journal of Language and Literacy, Computer Assisted Language Learning, Educational Technology \& Society, and Scandinavian Journal of Educational Research Published from 2003 until 2011. Only 15 of the 33 articles published in journals between 2003 and 2011 were focused on for this study. Nevertheless, the keywords video games and language learning were used to describe only 9 posts. Methodologically, most of the publications were reviews of literature accompanied by case studies and experimental studies. Several papers brought quantitative and qualitative methods together. Findings from all of the reviewed articles show that video games have potential as effective teaching aids and can motivate language learning students.

Kao (2014) researched the effects of digital game-based learning (DGBL) in the context of English as a Foreign Language (EFL). Twenty-five studies were included, resulting in a medium positive effect size $(d=0.695, p<.05$ under the model of fixed effect; $\mathrm{D}=0.777, \mathrm{p}<.05$ Under the random-effects model), indicated that $\mathrm{DGBL}$ is more efficient than conventional instructions, such as grammar translation methods or audio-lingual methods in EFL contexts. A coding scheme based on the link between taskbased language learning and DGBL was developed. To further investigate the effectiveness of the DGBL, six potential moderating variables were analyzed in three task characteristics. Among these potential moderating variables, the duration of treatment and linguistic knowledge of the characteristics of task involvement were found to influence the effectiveness of the DGBL. This meta analysis suggests that digital games should successfully acquire procedural knowledge of EFL learners undergoing DGBL's long duration of care. Future research will explore more distinctions in other possible moderating variables to provide a more detailed picture of what kinds of variables are important and what kinds are not.

In this meta-analysis, Clark, Smith and Killingsowth (2015) systematically reviewed the research on digital games and English language learning for K-16 students. They synthesized game-to-nongame comparisons (i.e., media comparisons) and game-togame comparisons (i.e. value-added comparisons). They used meta-regression models with random effects with accurate variance estimates to summarize overall effects and investigate possible moderator effects. The findings of a media analysis found that digital games improved student learning substantially in relation to the nongame conditions $(\mathrm{g}=0.33,95 \%$ confidence interval [ $0.19,0.48], k=57, n=209$ ). Value-added comparative results indicated inflammatory learning benefits associated with increased game designs ( $\mathrm{g}=0.34,95$ per cent confidence interval [ $0.17,0.51], \mathrm{k}=20, \mathrm{n}=40$ ). Moderator analysis showed that results ranged across different characteristics of game mechanics, visual and narrative characteristics, and characteristics of testing quality. Taken together, the results highlight both the learning affordances of games and the key role beyond the medium of design.

Clark and Douglas (2016) investigated meta-analysis. They have extensively analyzed digital games study and student learning for K-16 students. They synthesized game comparisons against nongame conditions (i.e., media comparisons) and improved game comparisons toward regular game designs (i.e., value-added comparisons). they used meta-regression models of random effects with accurate variance estimates to summarize the overall effects and explore possible moderator effects. Media comparison results indicated that digital games significantly increased student learning with respect to nongame conditions ( $\mathrm{gg}^{-}$ $=0.33,95$ percent confidence interval $[0.19,0.48], \mathrm{k}=57, \mathrm{n}=209$ ). Results from value-added comparisons revealed substantial learning advantages associated with increased game design ( $\mathrm{gg}=0.34,95 \%$ confidence interval $[0.17,0.51], \mathrm{k}=20, \mathrm{n}=40$ ). Moderator analysis showed that results ranged across different characteristics of game mechanics, visual and narrative characteristics, and characteristics of testing quality. Taken together, the findings illustrate both the learning affordances of games and the key role of beyond the medium of design. 


\subsection{Concluding remarks}

Many studies addressed the issue of evaluating the effectiveness of games. They studied the effect of using games as single studies. Previous studies focused on meta-analyzing studies about different methods and variables. However, the literature review refers to the fact that there is a limited number of studies on the meta analysis studies on games generally. To the researchers best knowledge, it appears that no studies were conducted about a meta analysis of games strategies in English language teaching/learning in EFL/ESL context in comprehensive way. This study purposed identifying the general trends, focus and description of research on games strategies using meta analysis design in the EFL/ESL context during the period 2000-2018. It examined strategies used, instrument of the study, year of publication, participants, design of the study, skills and areas analyzed in the study, length of the study, and effectiveness.

\section{Method}

\subsection{Design of the study}

This study metaanalyzed previous studies on the game-based studies available with regard to their methods and procedures. This aimed at cross-examining these studies on the basis of the eleven features, including strategy used, instrument, year of publication, publication year, participant, design of the study, area and skills analyzed in the study, length of the study and effectiveness. The research followed the empirical format of earlier literature on the use of games techniques in English language learning. This study shows tables describing all the enclosed study samples, which are seventy studies, study design, study intervention, and results. Then the reader can simply evaluate variations and similarities between individual studies, and determine variations in the study population, study design, or study intervention that may account for differences in the study results. The independent variable is a strategy used, instrument, year of publication, publication year, participant, design of study, area and skills analyzed in the study, length of the study and effectiveness. On the other hand, the means and majors are related to the nine aspects.

\subsection{Sample of the study}

Since the studies in this field were very limited, no exclusion criteria were adopted by the researchers. A sample of 70 resources for the 2000-2018 period. It is based on the meta analysis method. The study used 70 previous studies that could be obtained from available sources published in journals articles, conferences Proceedings and Graduate Thesis and Dissertation; see Table 1.

\section{Table 1: Studies by Type of Publication}

\begin{tabular}{|c|l|c|c|}
\hline No. & \multicolumn{1}{|c|}{ Type of Publication } & Frequency & percentage \\
\hline 1 & Conferences Proceedings & 55 & $84.9 \%$ \\
\hline 2 & Journal Article & 8 & $9.09 \%$ \\
\hline 3 & Graduate Thesis and Dissertation & 7 & $6.8 \%$ \\
\hline \multicolumn{2}{|c}{ Total } & $\mathbf{7 0}$ & $\mathbf{1 0 0} \%$ \\
\hline
\end{tabular}

\subsection{Instrumentation}

The study instrument is adapted from. The instrument was a listing of meta analysis containing a sample of earlier studies. Options examined overall trends, description and analysis of the instrument. The meta analysis checklist consisted of the following 9 options and their subsection: the strategies used, instrument of the study, year of publication, publication type, participant, design of the study, skills and areas analyzed in the study, and length of text, and effectiveness of the game method.

The instrument of the study was introduced to 8 specialists in English language curricula and instruction and English language at Al al-Bayt University, Yarmouk University, and Tafila University. They were asked to examine the instrument concerning the strategies used, instrument, year of publication, publication type, participant, design of the study, areas and skills analyzed in the study, and length of text. They recommended clarifying the rubrics and changing some features like designs and instruments used in the studies. To achieve reliability for the instrument, the reliability coefficients were calculated using two independent raters for the meta- analysis consequences. The two professionals were given random samples elicited from the sample studies; they were educated to rate these studies using the instrument of the study and its features. The meta analysis reliability between them was 0.89 .

\subsection{Procedures of the study}

The researchers reviewed the most common scientific databases publishing game related studies. These included the studies found in the University of Jordan Database, Yarmouk University Database, Al al-Bayt University Database, Muta' University Database, and Amman Arab University databases. The search was limited to the period 2000-2018. These databases have access to international sources and journals. The sample research was found in a number of journals and sources. The researchers used the following procedures: 
- Searching the Internet to identify the appropriate databases publishing studies related to using games in English language teaching and learning. Using the Google search engine to search for keywords, including games, was reset for other search attempts using individual keywords. The search engine showed the results obtained on the computer screen based on the keyword used in the search.

- To achieve the aims of the current study, the title of each study was browsed to identify its content, date of publication, as the sample studies used in the current study were limited to the period 2000-2018.

- $\quad$ The suitable studies were selected according to the selection criteria used.

- $\quad$ Sample studies were obtained to be analyzed in this study.

- $\quad$ The studies were investigated and categorized according to the variables used in the study instrument.

- $\quad$ The sample studies were coded according to the sub variables for each sub-question of the study.

- $\quad$ Their frequencies were calculated and listed in tables.

- $\quad$ Appropriate statistical analyses were conducted to get the results.

- $\quad$ Finally, findings were analyzed and discussed as per the questions of the study.

\subsection{Data Analysis}

The study used meta analysis method because it is the main tool for data analysis. As known, meta analysis could be a tool for data analysis in quantitative studies. Descriptive statistics, including frequencies and percentages were used to find if their important variations between frequencies of major of the features their sub-variables (strategies used, instrument, year of publication, publication type, participant, design of study, skills and areas analyzed in the study, and length of the study and effectiveness of the study).

\section{Findings of the Study}

This chapter shows the results of the study. The main question of the study sought to identify the general strategies, description and focus of research about games strategies in English language teaching, related to the following main features: strategies used, instrument, year of publication, publication type, participant, design of study, skills and areas analyzed in the study, and length of the study and effectiveness of the study. To answer the main question and its sub features, the frequencies and percentage of analysis components were calculated.

The question of the study focused on finding the strategies used in studies about the effectiveness of using games in English language teaching/learning. In order to answer this question, all strategy used in studies about games were first coded. The 70 studies were categorized according to the strategy used, including regular games and CALL games. The frequencies were counted for each strategy, and the percentages were then calculated. The frequency and the percentage for strategies used were then computed as shown in Table 1.

Table1: Frequencies and Percentages for the Strategies Used

\begin{tabular}{|c|l|c|c|}
\hline Rank & Experimental strategies & Frequency & Percentage \\
\hline 1 & Games (Regular) & 60 & $85.71 \%$ \\
\hline 2 & Games (CALL) & 10 & $14.29 \%$ \\
\hline \multicolumn{2}{c}{ Total } & $\mathbf{7 0}$ & $\mathbf{1 0 0 \%}$ \\
\hline
\end{tabular}

As can be seen in Table 1 the regular games had the highest frequency $(60,85.71 \%)$, while games (CALL) had the lowest frequency $(10,14.29 \%)$.

The question of the study focused on finding the instrument of the study used in studies about the effectiveness of using games strategies in English language teaching/learning. In order to answer this question, all the instrument of the study in studies about games strategies were first coded. The 70 studies were categorized according to the instrument of the study, including openended interview, questionnaire, and observation - check list. The frequencies were counted for each strategy, and the percentages were then calculated. The frequency and the percentage for the study instrument were then computed as shown in Table 2.

Table 2: Frequencies and Percentages for the Instrument of the Study

\begin{tabular}{|c|l|c|c|}
\hline Rank & \multicolumn{1}{|c|}{ Instrument of the Study } & Frequency & Percentage \\
\hline 1 & Test & 37 & $52.85 \%$ \\
\hline 2 & Questionnaire+Open-ended interview & 14 & $22.00 \%$ \\
\hline 3 & Test + Observation checklist + Open-ended interview & 3 & $3.28 \%$ \\
\hline 3 & Test + Observation checklist + Questionnaire & 2 & $2.85 \%$ \\
\hline
\end{tabular}




\begin{tabular}{|c|l|c|c|}
\hline 3 & Test + Questionnaire & 2 & $2.58 \%$ \\
\hline 6 & Observation checklist & 2 & $2.85 \%$ \\
\hline 6 & Test+ Observation checklist + Questionnaire & 2 & $2,85 \%$ \\
\hline 8 & Observation checklist + Questionnaire & 2 & $2,85 \%$ \\
\hline 8 & Observation checklist + Questionnaire & 1 & $1,42 \%$ \\
\hline 8 & Test + Open-ended interview & 1 & $1.42 \%$ \\
\hline 8 & Open-ended interview & 1 & $1,42 \%$ \\
\hline 8 & Questionnaire & 1 & $1,42 \%$ \\
\hline 8 & Observation checklist + Open-ended interview & 1 & $1,42 \%$ \\
\hline 8 & Questionnaire +Open-ended interview & $\mathbf{7 0}$ & $\mathbf{1 0 0} \%$ \\
\hline
\end{tabular}

Table 2 shows that the aspect test had the highest frequency $(37 ; 52.85 \%)$ of the instrument studies analyzed. The second highest frequency $(14 ; 20,00 \%)$ was for questionnaire and open-ended interviews. This followed by test, observation checklist, and open-ended interview had the frequency $(3 ; 4.28 \%)$. In addition, the aspects test, questionnaire, observation checklist had the frequency $(2 ; 2,85 \%)$. The lowest frequency was for the aspects of open-ended interviews, questionnaires, and observation checklists $(1 ; 42 \%)$.

The question of the study focused on finding the years of the study used in studies about the effectiveness of using games strategies in English language teaching/learning. In order to answer this question, all the years of the study in studies about games strategies were first coded. The 70 studies were categorized according to the year of the study, including 2000 to 2018. The frequencies were counted for each strategy, and the percentages were then calculated. The frequency and the percentage for years of the study were then computed as shown in Table 3.

Table 3: Frequencies and Percentages for the Year of the Study

\begin{tabular}{|c|l|c|c|}
\hline Rank & Year of the Study & Frequency & Percentage \\
\hline 1 & 2000 & 5 & $7.14 \%$ \\
\hline 2 & 2001 & 4 & $5.71 \%$ \\
\hline 3 & 2002 & 3 & $4.29 \%$ \\
\hline 4 & 2003 & 5 & $7.14 \%$ \\
\hline 5 & 2004 & 2 & $2.86 \%$ \\
\hline 6 & 2005 & 4 & $5.71 \%$ \\
\hline 7 & 2006 & 3 & $4.29 \%$ \\
\hline 8 & 2007 & 4 & $5.71 \%$ \\
\hline 9 & 2008 & 4 & $5.71 \%$ \\
\hline 10 & 2009 & 3 & $4.29 \%$ \\
\hline 11 & 2010 & 3 & $4.29 \%$ \\
\hline 12 & 2011 & 4 & $5.71 \%$ \\
\hline 13 & 2012 & 3 & $4.29 \%$ \\
\hline 14 & 2013 & 3 & $4.29 \%$ \\
\hline 15 & 2014 & 4 & $5.71 \%$ \\
\hline 16 & 2015 & 7 & $10.00 \%$ \\
\hline 17 & 2016 & 9 & $12.86 \%$ \\
\hline & Total & $\mathbf{7 0}$ & $\mathbf{1 0 0 \%}$ \\
\hline
\end{tabular}

Table 3 shows that the highest frequency comes in favor of the years 2015 and 2016 as compared with 2000, 2003, 2004 while, there is a balance in the distribution of observed frequencies in proportion with the expected frequencies of publication year levels 2001, 2005, 2008, 2011, and 2014.

The question of the study focused on finding the type of publication used in studies about the effectiveness of using games strategies in English language teaching/learning. In order to answer this question, all the type of publication in studies about games strategies were first coded. The 70 studies were categorized according to the type of publication, including conference proceedings, journal article, and thesis defended in universities. The frequencies were counted for each strategy, and the 
percentages were then calculated. The frequency and the percentage for type of publications were then computed as shown in Table 4.

Table 4: Frequencies and Percentages for the Type of Publication

\begin{tabular}{|c|l|c|c|}
\hline Rank & \multicolumn{1}{|c|}{ Type of Publication } & Frequency & Percentage \\
\hline 1 & Conference Proceedings & 55 & $78.57 \%$ \\
\hline 2 & Journal Article & 8 & $11.43 \%$ \\
\hline 3 & Thesis Defended in Universities & 7 & $10.00 \%$ \\
\hline \multicolumn{2}{r|}{ Total } & $\mathbf{7 0}$ & $\mathbf{1 0 0} \%$ \\
\hline
\end{tabular}

Table 4 shows that the aspect Conference Proceedings had the highest frequency 55; (78.57 \%). The second highest frequency 8 ; (11.43\%) was for the aspect journal article. The lowest frequency was for the aspect thesis defended in universities (7, 10.00\%).

The question of the study focused on finding the type of Participants used in studies about the effectiveness of using games strategies in English language teaching/learning. In order to answer this question, all the types of Participants in studies about games strategies were first coded. The 70 studies were categorized according to the type of publication, including EFL learner and ESL learner. The frequencies were counted for each strategy, and the percentages were then calculated. The frequency and the percentage for type of Participants were then computed as shown in Table 5.

Table 5: Frequencies and Percentages for the Type of Participants

\begin{tabular}{|l|c|c|c|}
\hline Rank & Type of Participants & Frequency & Percentage \\
\hline 1 & EFL learners & 55 & $78.57 \%$ \\
\hline 2 & ESL Learners & 12 & $17.14 \%$ \\
\hline \multicolumn{2}{|c|}{ Total } & $\mathbf{6 7}$ & $\mathbf{1 0 0 \%}$ \\
\hline
\end{tabular}

This Table shows that the highest frequency for the aspect EFL learners is $(55 ; 78.57 \%)$, while the lowest frequency for the aspect ESL learners is $(12 ; 17.14 \%)$.

The question of the study focused on finding the Participants' Level used in studies about the effectiveness of using games strategies in English language teaching/learning. In order to answer this question, all the Participants' Level in studies about games strategies were first coded. The 70 studies were categorized according to the Participants' Level, including school, undergraduate and graduate. The frequencies were counted for each strategy, and the percentages were then calculated. The frequency and the percentage for Participants' Level were then computed as shown in Table 6.

Table 6: Frequencies and Percentages for the Participants' Level

\begin{tabular}{|c|l|c|c|}
\hline Rank & Participants Level & frequency & Percentage \\
\hline 1 & School & 40 & $57.14 \%$ \\
\hline 2 & Undergraduate & 10 & $14.29 \%$ \\
\hline 3 & Graduate & 10 & $14.29 \%$ \\
\hline \multicolumn{2}{r}{ Total } & $\mathbf{6 0}$ & $\mathbf{1 0 0} \%$ \\
\hline
\end{tabular}

Table 6 shows that there is no balance in the distribution of observed frequencies in combination with the expected frequencies of participants' levels. The results favoured school level (40;57.14\%) compared with Graduate level (10;14.29\%) and undergraduate level.

The question of the study focused on finding the Participants' Number used in studies about the effectiveness of using games strategies in English language teaching/learning. In order to answer this question, all the Participants' Number in studies about games strategies were first coded. The 70 studies were categorized according to the Participants' Number, including 16 and more and 1 to 13 . The frequencies were counted for each strategy, and the percentages were then calculated. The frequency and the percentage for Participants' Number were then computed as shown in Table 7. 
Table 7: Frequencies and Percentages for the Participants' Number

\begin{tabular}{|c|c|c|c|}
\hline Rank & Number of Participants & frequency & Percentage \\
\hline 1 & 16 and more & 50 & $71.43 \%$ \\
\hline 2 & 1 to 13 & 13 & $18.57 \%$ \\
\hline \multicolumn{2}{r|}{ Total } & $\mathbf{6 3}$ & $\mathbf{1 0 0 \%}$ \\
\hline
\end{tabular}

Table 7 shows no balance in the distribution of observed frequencies for the participants' number. The highest frequencies favour category 16 and more as compared with 1 to 13 participants.

The question of the study focused on finding the Design of the Study used in studies about the effectiveness of using games strategies in English language teaching/learning. In order to answer this question, all the Design of the Study in studies about games strategies were first coded. The 70 studies were categorized according to the Participants' Number, including Control/Experimental Pre-/Post-test, Qualitative (Open-ended Interview) One-Group Pre-Posttest and Descriptive (Questionnaire). The frequencies were counted for each strategy, and the percentages were then calculated. The frequency and the percentage for design of the study were then computed as shown in Table 8.

Table 8: Frequencies and Percentages for the Design of the Study

\begin{tabular}{|c|c|c|c|}
\hline Rank & Design of the Study & Frequency & Percentage \\
\hline 1 & $\begin{array}{l}\text { Test+ Observation checklist+ } \\
\text { Questionnaire }\end{array}$ & 2 & $2.85 \%$ \\
\hline 2 & Observation checklist + Questionnaire & 2 & $2.85 \%$ \\
\hline 3 & Test + Questionnaire & 2 & $2.85 \% 8$ \\
\hline 3 & $\begin{array}{l}\text { Test }+ \text { Observation checklist }+ \\
\text { Questionnaire }\end{array}$ & 2 & $2.85 \%$ \\
\hline 3 & $\begin{array}{l}\text { Test }+ \text { Observation checklist }+ \text { Open- } \\
\text { ended interview }\end{array}$ & 3 & $4.28 \%$ \\
\hline 6 & Observation checklist & 2 & $2.85 \%$ \\
\hline 6 & $\begin{array}{l}\text { Observation checklist }+ \text { Open-ended } \\
\text { interview }\end{array}$ & 1 & $1,42 \%$ \\
\hline 8 & Test + Observation checklist & 1 & $1,42 \%$ \\
\hline 8 & Observation checklist + Questionnaire & 1 & $1,42 \%$ \\
\hline 8 & Questionnaire + Open-ended interview & 14 & $20.00 \%$ \\
\hline 8 & Observation checklist & 1 & $1,42 \%$ \\
\hline 8 & Questionnaire & 1 & $1,42 \%$ \\
\hline 8 & Test & 37 & $52.85 \%$ \\
\hline 8 & Questionnaire +Open-ended interview & 1 & $1,42 \%$ \\
\hline \multicolumn{2}{|l|}{ Total } & 70 & $100 \%$ \\
\hline
\end{tabular}

Table 8 shows that the aspect test had the highest frequency $(37 ; 52.85 \%)$ of the design of the study analyzed. The second highest frequency $(14 ; 20,00 \%)$ was for questionnaire and open-ended interview. This followed by test, observation checklist, and open-ended interview had the frequency $(3 ; 4.28 \%)$. In addition, the aspects test, questionnaire, observation check list had the frequency $(2 ; 2,85 \%)$. The lowest frequency was for the aspects of open-ended interviews, questionnaires, and observation checklists (1;42\%).

The question of the study focused on finding the Skills and Areas used in studies about the effectiveness of using games strategies in English language teaching/learning. In order to answer this question, all the Skills and Areas in studies about games strategies were first coded. The 70 studies were categorized according to the Participants' Number, including listening, grammar, speaking, integrated language skills, writing, vocabulary and reading. The frequencies were counted for each strategy, and the percentages were then calculated. The frequency and the percentage for Skills and Areas were then computed as shown in Table 9. 
Table 9: Frequencies and Percentages for the Skills and Areas

\begin{tabular}{|c|l|l|c|}
\hline Rank & \multicolumn{1}{|c|}{ The skill and area } & frequency & Percentage \\
\hline 1 & Listening & 3 & $4.29 \%$ \\
\hline 2 & Grammar & 2 & $2.86 \%$ \\
\hline 3 & Speaking & 4 & $5.71 \%$ \\
\hline 4 & Integrated Language Skills & 10 & $14.29 \%$ \\
\hline 5 & Writing & 10 & $14.29 \%$ \\
\hline 6 & Vocabulary & 20 & $28.57 \%$ \\
\hline 7 & Reading & 21 & $30.00 \%$ \\
\hline & \multicolumn{2}{|c|}{} \\
\hline
\end{tabular}

According to the result in Table 9, the highest frequency score was 20 (.28.57\%) for aspect 1 "It is easy to access the meaning of words while regarding in CALL classes". The lowest frequency (2.2.86\%) was for aspect 4 prefer to study via computer.

The question of the study focused on finding the length of text used in studies about the length of text strategies in English language teaching/learning. In order to answer this question, all the lengths of text in studies about games strategies were first coded. The 70 studies were categorized according to the Participants' Number, including 11 to 20 (5001-10000 words), 1 to 10 (1-5000 words), More than 30 (More than 15000 words) and 21 to 30 (10001-15000 words). The frequencies were counted for each strategy, and the percentages were then calculated. The frequency and the percentage for the length of text were then computed, as shown in table 11.

Table 10: Frequencies and Percentages for the length of text

\begin{tabular}{|c|c|c|c|}
\hline Rank & Length of Text by Pages & Frequency & Percentage \\
\hline 1 & 11 to $20(2,645-4,729$ words) & 30 & $42.86 \%$ \\
\hline 2 & 1 to $10(1-2,645$ words) & 27 & $38.57 \%$ \\
\hline 3 & More than 30 (More than 6,390 words) & 6 & $8.57 \%$ \\
\hline 4 & 21 to 30 (2,645 -6,390 words) & 7 & $10.00 \%$ \\
\hline \multicolumn{2}{r|}{ Total } & $\mathbf{7 0}$ & $\mathbf{1 0 0 \%}$ \\
\hline
\end{tabular}

Table 11 shows frequencies of the possibility of occurrence of the length of the text in pages, which means that there is no balance in the good distribution of observed. The results come in favor of 11 to 20 pages (2,645-4,729 words) and 1 to 10 page (1-2,645 words) as compared with a frequency of 21 to 30 pages (2,645 -6,390 words), while there is a balance in the good distribution of observed frequencies in proportion to the expected frequencies for the length of text in more than 30 (more than 6,390 words). The question of the study focused on finding the effectiveness of games used in studies about the effectiveness of using games strategies in English language teaching/learning. In order to answer this question, all the effectiveness of games in studies about games strategies were first coded. The 70 studies were categorized according to the Participants' Number, including more effective games than other methods. Games are as effective as other methods (no significant differences). The frequencies were counted for each strategy, and the percentages were then calculated. The frequency and the percentage for effectiveness of Games were then computed as shown in Table10.

Table 11: Frequencies and Percentages for the Effectiveness of Games

\begin{tabular}{|c|l|c|c|}
\hline Rank & \multicolumn{1}{|c|}{ Result of the Study } & Frequency & Percentage \\
\hline 1 & $\begin{array}{l}\text { Games are more effective } \\
\text { than other methods }\end{array}$ & 68 & $97.14 \%$ \\
\hline 2 & $\begin{array}{l}\text { Games are as effective as } \\
\text { other methods (no significant differences) }\end{array}$ & 2 & $2.86 \%$ \\
\hline \multicolumn{2}{|c|}{ Total } & $\mathbf{7 0}$ & $\mathbf{1 0 0 \%}$ \\
\hline
\end{tabular}

As can be seen in Table 9, certain aspects had lower and higher frequencies when compared with the general student's attitude frequency. For example, aspect games are more effective than other methods had the highest frequency score (68. $97.14 \%$ ). While games are as effective as other methods (no significant differences), aspects had the lowest frequency score. (2. 2.86\%). 


\section{Discussion, Conclusions and Recommendations}

The question of the study sought to investigate the type of publication in studies about games. The results revealed that there were differences in frequencies in games studies due to the type of conference proceeding in favor of articles published in journals. Most games were published in the conference proceeding. This indicated that those studies received more attention through the peer review process conducted by conference proceedings before accepting the papers than other types such as proceedings published in conferences, which usually receive less attention. Unlike theses or dissertations written by graduate students, journal articles are usually written by competent researchers and lecturers working in universities and educational institutions. The least frequent type of publication in the sample studies about games was thesis defended in universities. There was only 7 thesis defended in universities.

This might reflect the fact that supervisors and students were hesitant to write more conference proceedings on games strategies.

The question of the study also focused on design of the study used in games. The findings of the study revealed that the most frequent design is test $37 ;(52,85 \%)$. This indicated differences in frequencies in games due to design of the study in favor of the experimental design. This may reflect the assumption that the goal of games was to measure the effect by having such a design as compared with other designs. This also implies that researchers did not focus on descriptive studies, which measure participants' attitude toward games; rather, most researches focused on test which measures effectiveness of using the games method in developing EFL/ESL learners' linguistic abilities. This seems that experimental studies are based on the test as a measure instrument in their design.

The question of the study solicited to find the Skills and Areas in. the sample studies about the effectiveness of games in English language teaching/learning. The findings revealed differences between the frequencies of games studies due to the skills and areas that the study deals with in favor of Vocabulary and Reading skills. This was followed by integrated language skills and Writing. However, there was a shortage of studies related to Listening, Speaking. This may be due to the difficulty of applying such a strategy in such skills and areas. Maybe, it is quite unusual to use the games in teaching the skills and areas of Grammar.

The question of the study also focused on the type of Participants in studies about games. The findings of the study revealed that there were differences between games frequencies due to participant's type (ESL learner's vs EFL learners) in favor of EFL students. This implies that the games method is found to be a suitable strategy to be used in learning English language by EFL learners. EFL education can be defined as the English language which is taught and learnt in a country where the official language is not English, like China, and Japan. This differs from ESL education, which refers to English language that is taught and learnt in an English-speaking country, like UK, and USA, the language environment is the key factor in distinguishing the two terminologies. Making EFL education more effective is the primary concern for doing research related to games.

Furthermore, the major question of the study concentrates on the level of participants in studies about the effect of using games strategies on EFL settings and contexts. The results indicated differences between frequencies of games due to participants' level (school, undergraduate and graduate) in favor of school. This result is because school students may need more tangible help in learning the English language. Games strategies seem to offer them more help than other regular communicative methods of teaching; it seems it helped them see and understand the relationship between different concepts and terminologies, a step which might encourage researchers to use the games in helping EFL learners develop and learn different language skills, areas and abilities.

Moreover, the results show that there were differences between frequencies of games due to participant's number, in favor of the category 16 and more with 50 frequencies. The least frequent participants' number was the category 1-13 with 13 frequencies. This also reflects that studies based on few participants such as qualitative and case studies were quite limited in the sample analyzed in the current study.

The question of the study also focused on the year of publication in studies about games strategies. The findings of the study indicated that there were differences between frequencies due to year of publication in favor of the years 2015-2016. This means that they had the highest frequency of studies about the effectiveness of using games strategies in English language teaching/learning. There was a lack in the attention of researchers in the early years during the period 2002-2012. As the majority of games studies were conducted after 2015, this reflects the fact that there is a recent interest by researchers to conduct more research in using games strategies for teaching EFL learners. The findings of the study also show that in the recent years 2010-2014, there was an outpouring interest of researchers about using games strategies. In EFL contexts, a fact may show more interest in using the explicit learning technique in teaching and learning vocabularies in English language classrooms. 
The question of the study solicited to find length of text (number of pages and words) used in studies about games strategies. The result of the study showed that there were differences between games studies frequencies due to length of text in favor of the category 1-10 pages (1-2,645 words). This may be due to the fact that the most frequent research type was published in journals, whose terms for publication do not usually exceed a certain number of words and pages. It is around 15 pages $(2,645$ 4,729 words), so this category (10 pages (2,645-4,729 words) obtained the highest frequency of studies conducted about the effect of using games strategies in the English language teaching.

The question of the study focused on the effectiveness of using games on English language teaching/ learning. The findings of the study indicated that there were differences between games studies frequencies due to the result of the study in favor of games is more effective than other method. This was the most frequent result that got the higher frequencies, and this result shows that games are more effective in teaching English as a foreign language than other regular instruction methods adopted by teachers and lecturers in the sample analyzed in the current study. Again, this reflects the need to adopt the strategies of the game as a method that may help learners, especially in EFL settings and contexts.

The findings of the study indicated that there were differences in games frequencies due to Instrument of the study in favor of test as compared with a questionnaire. This finding shows that test is the most effective instrument used to measure the effect of using games method in EFL settings. However, there is a balance between the observation chick list and open-ended interview of the levels of the study instruments (open-ended interview).

\section{Conclusions and recommendations}

Meta-analysis design is very useful in finding the general trends, description and focus in studies about the effectiveness of games in English language teaching/ learning than the analysis of any single study. It provides a technique for aggregating many words of text into fewer content categories systematically. This enables researchers to shift through large volumes of data systematically. Games studies published in conference proceedings received more attention than other types of publications. The most popular design used in games studies was experimental, including more than 13 participants. Games studies dealt with vocabulary, reading, writing and integrated language, but there is a shortage in other skills and areas. Games studies focused on EFL participants, but there is a shortage in ESL contexts. School-level has more attention as compared with other levels (undergraduate and graduate). Games studies have paid more attention to researchers during the last 2 years, making it a recent trend in English language learning. Most results of games studies show that games strategies are more effective than other regular instruction methods. Games studies used the test as an instrument of the study compared with other instruments (openended interview, questionnaire and observation checklist). Most studies used regular games teaching as compared with computerized games strategies. More games studies focused on texts of 11-20 pages (2,645-4,729 words) while few focused on longer texts of more than 30 pages.

In light of the study findings, researchers should pay attention to the text type in games studies by conducting more research in this area, including more conference proceedings and theses. There is a need for diversification in the research tools such as questionnaires and checklists in studies about games strategies. More research is needed in the area of meta-analysis using learning strategies, including using different methods and languages other than games. There is a high need for conducting studies that develop listening and grammar using games. Researchers are also advised to use meta analysis to know about the advantages and disadvantages of games in EFL contexts. Based on the study's findings, the researchers recommend that curriculum designers and decision-makers integrate the game's strategy in curricula and design materials and hold workshops for supervisors about games. The researchers also recommend supervisors hold training courses, provide materials and books for teachers about games, and organize workshops to introduce teachers to new teaching methods, including games. Furthermore, the researchers recommend that teachers use games to teach various aspects of English, change the traditional teaching method, and develop visual thinking skills in all aspects of English and other subjects using games and present new methods in teaching vocabulary.

There are a number of limitations to the generalizability of the results of this study. The design of sample studies included observation checklist, questionnaire, test, open-ended interview. The study only targets the publications in journals, theses and dissertations, and conferences proceedings during the period 2000-2018. Only the intended skills and areas are dealt with including, vocabulary, pronunciation, writing, grammar, integrated language learning, listening, reading, and writing. The design of the current study is limited to using meta analysis. Finally, investigations here are limited to studies on games strategies in the broadest sense over the last 18 years. The study is limited to researches using games strategies. In this study, the sample included non-native speakers of researches about English as a foreign language including ESL and EFL learners. 


\section{References}

[1] Ayaz M.F. , \& Şekerci H. (2015). The Effects of the Constructivist Learning Approach on Student's Academic Achievement: A Meta Analysis Study, The Turkish Online Journal of Educational Technology, 14(4):143- 156.

[2] Atake, K. (2003) Using Games to teach English in Japanese Junior High School.

[3] Abdul Aziz, A. (2016). The use of Mind Mapping Technique in increasing Students' Vocabulary, Journal of Education and Social Sciences, 4,(2), p.105-113. A model to guide self-care readiness. Health Care for Women International, 6(1-3), 151-163.

[4] Borenstein, M., Hedges, L. V., Higgins, J. P., \& Rothstein, H. R. (2011). Introduction to meta-analysis. John Wiley \& Sons.

[5] Bacha, J. (2002). Play and Affect in Language Learning. MATESOL International Policy Studies Candidate, Educational Development Monterey Institute of International.

[6] Clark, D. B., Tanner-Smith, E. E., \& Killingsworth, S. S. (2016). Digital games, design, and learning: A systematic review and meta-analysis. Review of Educational Research, 86(1), 79-122.

[7] Clark, Douglas B., Emily E. Tanner-Smith, and Stephen S. Killingsworth. Digital games, design, and learning: A systematic review and metaanalysis. Review of educational research 86.1: 79-122.

[8] Chian-Wen, K. A. O. (2014). The effects of digital game-based learning task in English as a foreign language contexts: $A$ meta-analysis. Education Journal, 42(2), 113-141.

[9] Darusalam, G. (2013). Potential of video games in learning Bahasa Melayu vocabulary among international university students in Malaysia: A meta analysis of selected journals. TOJET: The Turkish Online Journal of Educational Technology, 12(4).

[10] Doughty, C.J, \& Long, M.J. (2003). Optimal psycholinguistic environments for distance foreign language learning. Language learning \& Teachnology, $7(3), 50-80$.

[11] Felix, U. (2005). Analysing recent CALL effectiveness research-towards a common agenda. Computer assisted language learning, 18(1-2), 1-32.

[12] Fuertes, Jairo N., et al. A meta-analysis of the effects of speakers' accents on interpersonal evaluations. European Journal of Social Psychology 42.1 (2012): 120-133.

[13] Glass, G. V. (1976). Primary, secondary, and meta-analysis of research. Educational.

[14] Graham, Steve, and Karin Sandmel. The process writing approach: A meta-analysis. The Journal of Educational Research 104.6 (2011): $396-$ 407.

[15] Graham, Steve, and Karin Sandmel. The process writing approach: A meta-analysis. The Journal of Educational Research 104.6 (2011): $396-$ 407.

[16] Glass, G. V. (1976). Primary, secondary, and meta-analysis of research. Educational Researcher, 5(10), 3-8.

[17] Hunter, J. E., Schmidt, F. L., \& Jackson, G. B. (1982). Meta-analysis: Cumulating research.

[18] Stern, P. N., \& Harris, C. C. (1985). Women's health and the self-care paradox.

[19] Hunter, J. E., Schmidt, F. L., \& Jackson, G. B. (1982). Meta-analysis: Cumulating research findings across studies (Vol. 4). Thousand Oaks, CA: Sage Publications.

[20] Han, Han and Cheng, Liying (2011) Tracking the Success of English Language Learners within the Context of the Ontario Secondary School Literacy Test, Canadian and International Education / Education canadienne et international 40(1), Article 6.

[21] Liao, Y. K. (2010, March). Game-based learning vs. traditional instruction: A meta-analysis of thirty-eight studies from Taiwan. In Society for Information Technology \& Teacher Education International Conference (pp. 1491-1498). Association for the Advancement of Computing in Education (AACE).

[22] Nematollahi , B, Behjat, F, \& Kargar,A (2017) A Meta Analysis of Vocabulary Learning Strategies of EFL Learners English Language Teaching; International Journal of Educational Investigations 10(5), 1-10.

[23] Norris, J. M., \& Ortega, L. (2000). Effectiveness of L2 instruction: A research synthesis.

[24] Norris, J. M., \& Ortega, L. (2000). Effectiveness of L2 instruction: A research synthesis and quantitative meta-analysis. Language Learning, 50(3), 417-528. doi: 10.1111/ 0023-8333.00136

[25] Paterson, B., Thorne, S., Canam, C., \& Jillings, C. (2001) Meta-Study of qualitative health

[26] Slavin, R. E., \& Cheung, A. (2003). Effective Reading Programs for English Language Learners: A Best-Evidence Synthesis.

[27] Yun, J. (2010). The effects of hypertext glosses on L2 vocabulary acquisition: A meta analysis. Unpublished thesis, University of Kansas.

[28] Vogel, J. J., Vogel, D. S., Cannon-Bowers, J., Bowers, C. A., Muse, K., \& Wright, M. (2006). Computer gaming and interactive simulations for learning: A meta-analysis. Journal of Educational Computing Research, 34(3), 229-243. 